\title{
Democracia: transformações passadas, desafios presentes e perspectivas futuras
}

JOHN MARKOFF"

\section{Resumo}

O campo conceitual das análises sobre a democracia, de um modo geral, tem sido delimitado territorialmente. Para a democracia antiga, o território foi aquele da cidade-estado; para a democracia moderna, um estado nacional. Ainda que, a partir do final do século 18, a democracia tenha se constituído em um conjunto de instituições e de práticas muito diferentes daquelas da democracia antiga, e embora a democracia moderna venha sofrendo contínuas e significativas mudanças, a noção de territorialidade delimitada persistiu como pressuposto central. No início do século 21, no entanto, há muitas razões para prever uma profunda mudança conceitual. A rede de conexões transnacionais, o desenvolvimento de estruturas transnacionais de tomada de decisão (da UE ao FMI) e a enorme disparidade de riqueza e poder entre os países estão colocando em questão a democracia dos estados nacionais. Embora a onda multicontinental de democratização do final do século 20 tenha produzido, em termos geográficos, a mais disseminada instituição de governos nacionais democráticos de toda a história, pesquisas de opinião em muitos países revelam uma grande insatisfação com a democracia praticada atualmente, não só nos países recentemente democratizados, mas também naqueles de maior tradição democrática. Há quem venha sugerindo a necessidade de democratização das estruturas transnacionais. Mas, faz sentido a existência de democracia em uma escala que ultrapasse a dos estados nacionais? Na esfera conceitual, há muitas razões para ceticismo. Entre as ques-

\footnotetext{
* Pós doutor em Sociologia. Professor do Departamento de Sociologia da Universidade de Pittsburg. (EUA) E-mail: jm2@pitt.edu.
} 
tões suscitadas estão: se a fraqueza das solidariedades e identidades transfronteiriças impediria uma democracia transfronteiriça; se estruturas administrativas de vasto alcance geográfico poderiam ser efetivamente submetidas ao escrutínio e controle cidadãos; e se os estados ricos e poderosos aceitariam estruturas maiores que limitassem sua autonomia.

Palavras-chave: Democracia. Globalização. Cidadania. Direitos. Movimentos sociais.

\section{Democracy's Past Transformations, Present Challenges and Future Prospects ${ }^{1,2, v}$}

\section{Abstract}

The conceptual field for discussions of democracy has generally been territorially delimited. For ancient democracy the territory was that of a city-state, for modern democracy a national state. Although modern democracy has from the late eighteenth century been in many ways quite a different set of institutions and practices than ancient democracy and although modern democracy has continually undergone significant change, the notion of delimited territoriality has remained a central assumption. In the early twenty-first century, however, there are many reasons to anticipate a major conceptual shift. The web of transnational connection, the development of transnational structures of decision-making (from the EU to the IMF), and the vast disparity in wealth and power among the national states are calling into question the democracy of the national states. Although the multicontinental wave of democratizations of the late twentieth century brought about the most geographically extensive implantation of democratic national governments in history, public opinion research in many countries shows significant dissatisfaction with democracy as currently practiced, not just in recently democratized countries but in the more established democracies as well. Some are suggesting that what is needed is the democratization of transnational structures. But can democracy meaningfully exist on a scale beyond the national states? On the

\footnotetext{
${ }^{1}$ Uma versão anterior deste trabalho foi apresentada na reunião da International Sociological Association, em Göteborg, Suécia, em julho de 2010.

${ }^{2}$ Sou grato a Joshua Dubrow e a Jackie Smith por seus comentários às primeiras versões.

v Tradução de Regina B. Vargas
} 
conceptual level, there are many reasons to be skeptical. Issues include whether the weakness of cross-border solidarities and identities preclude cross-border democracy; whether administrative structures of vast geographic scope can be made genuinely accountable to citizenry; and whether wealthy and powerful states will accede to larger structures constraining their autonomy.

Keywords: Democracy. Globalization. Citizenship. Rights. Social movements.

\section{Fundamentos conceituais da democracia moderna}

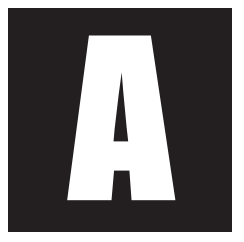

história da democracia nunca foi contínua ou simples. É de conhecimento geral que, a começar por Portugal, Grécia e Espanha, nos anos 1970, aumentou muito o número de países democráticos no mundo. No início da década de 1990, houve quem proclamasse que a história praticamente acabara, que a luta por democracia simplesmente havia triunfado em boa parte do mundo e que, cedo ou tarde, o restante dele se adequaria $^{3}$. Mas, também nos anos 1990, cientistas políticos começaram a observar um profundo descontentamento com as práticas das instituições democráticas. Os descontentes encontravam-se não só nos países em que a democracia fora recentemente ou novamente instalada, ou onde ela era instável ou vacilante, como também naqueles com tradição democrática de longa data (Pharr; Putnam, 2000; Norris, 1999; Nye Jr.; Zelikow; King, 1997; Clarke et al., 1995) ${ }^{4}$. Outros cientistas sociais passa-

\footnotetext{
${ }^{3}$ Em 1989, Francis Fukuyama (1989), em um ensaio intitulado "O fim da História?", indagava se o que ele via como uma longa luta entre democracia e alternativas nocivas fora, em essência, vencido. Contudo, no título de seu livro publicado três anos depois, ele suprimiu a interrogação (Fukuyama, 1992).

${ }^{4}$ Os EUA foram pioneiros no interesse acadêmico sobre esta questão (Lipset; Schneider, 1983). Os pesquisadores logo observaram algo similar no Canadá (Adams; Lennon, 1992) e, depois, na Europa (Norris, 1999). Dalton (2004, p. 191) resume assim essa pesquisa: Por meio de
} 
ram a apontar que períodos de avanço democrático, no passado, foram seguidos por períodos de retrocesso, e que as aspirações democráticas do passado foram, muitas vezes, sufocadas ${ }^{5}$. Observou-se que a democracia nem sempre entregou o que seus adeptos esperavam dela e nem sempre teve as consequências salutares que seus teóricos previam ${ }^{6}$, o que gerou toda uma literatura de análise sobre a qualidade da democracia (por exemplo, O’Donnell; Cullell; lazzetta, 2004). Observou-se, também, que aquilo que as pessoas entendem por democracia varia de um lugar para outro, ao longo do tempo e, até mesmo, de uma pessoa para outra (por exemplo, Collier; Levitsky, 1997; Hanson, 1985). Um certo cientista passou a indagar-se se democracia teria, afinal, algum significado. Análises da definição levam a redescobrir a afirmação do filósofo W.B. Gallie (1956) de que democracia constitui um excelente exemplo daquilo que ele denominou conceitos essencialmente contestados, sobre os quais os debates são insolúveis, mas inevitáveis por tratarem-se de conceitos relevantes.

Desenvolverei, aqui, algumas ideias sobre os rumos da democracia no século 21. Mas, antes, farei uma retrospectiva histórica dos significados de democracia. Iniciarei em 1780, vindo até os dias de hoje e, em seguida,

praticamente qualquer medida, tanto a fé e a confiança do público nos políticos, nos partidos e nas instituições políticas como seu apoio aos mesmos erodiram-se ao longo da última geração. Ver, porém, Norris (2011), para ressalvas importantes.

${ }^{5}$ Ao registrar reveses do passado, Huntington (1991, p. 290-294) foi um dos primeiros a levantar esta questão. Diamond (2008, p. 56-87) caracteriza o início do século 21 como um momento de recessão democrática. Tilly (2007) destaca a ocorrência frequente de episódios de desdemocratização, a partir do século 19. A análise realizada por Przeworski (2010, p. 56-59) sobre dados de participação eleitoral em todos os países com eleições parlamentares, desde o início do século 19, revela que, depois de um século e meio de participação ascendente - entendida como a proporção de votantes que efetivamente comparecem às urnas - a tendência mundial reverte-se, a partir de 1978, quando a participação passa a decrescer. Enquanto a democracia disseminou-se no final do século 20, a participação naquilo que é visto como sua instituição central declinou.

${ }^{6}$ Assim, para a questão 'O que devemos esperar de governos democráticos?', respondo: desenvolvimento, não; racionalidade, não; prestação de contas, pouca; igualdade, talvez. (Przeworski, 2007, p. 475). 
especulando sobre o futuro. Por que a década de 1780? Porque foi nessa época que a palavra democrata tornou-se comum, o que nos sugere algo importante (Palmer, 1953; Conze; Koselleck, 1972-1984, v. 4, p. 821-899). Democracia é uma palavra muito antiga, mas o uso corriqueiro de "democrata" é muito mais recente, remontando à época em que algumas pessoas buscavam dar lugar à democracia na prática efetiva dos estados nacionais, enquanto outras tentavam impedir isso (Markoff, 1996) ${ }^{7}$.

O que os primeiros democratas modernos do século 18 queriam dizer com democracia? ${ }^{8}$ Eles acreditavam saber algumas coisas importantes sobre o significado de democracia, pelo que sabiam sobre os modelos antigos ${ }^{9}$. Ao refletirem sobre efetivar a democracia no mundo moderno, eles seguiam algumas daquelas grandes ideias, mas rejeitavam definitivamente outras. Qual era a noção desses autores sobre a democracia antiga?

\footnotetext{
${ }^{7}$ Iniciar com as palavras "democrata" e "democracia" leva-nos a focar nos conhecimentos do século 18 sobre a Antiguidade, a fonte do segundo termo. Deve-se observar que a tomada coletiva de decisões, nas formas que configuram a história da democracia, precedeu a experiência ateniense e é muito mais diversa geograficamente do que relatam muitos de seus registros. Para um importante resgate, ver Isakhan e Stockwell (2011).

${ }^{8}$ Como "democracia" portava usualmente uma conotação negativa associada à insurgência e à espoliação legalizada dos em melhor situação pelos que se encontram em pior situação, o termo "democrata" tanto podia ser uma acusação quanto uma afirmação, e muitos dos que as gerações posteriores veriam como fundadores da democracia moderna negavam este rótulo. Uma narrativa abrangente da quase global aceitação do termo desde os anos 1780 ainda aguarda seus historiadores, mas há enfoques bastante sugestivos como os de Dunn (2005) e de Hanson (1985).

${ }^{9} \mathrm{O}$ conhecimento específico das instituições políticas atenienses aprofundou-se desde o final do século 18, a princípio, de forma gradual, pela exaustiva varredura das fontes disponíveis por acadêmicos do século 19 e, depois, subitamente, através da descoberta casual do minucioso estudo de Aristóteles e seus discípulos, a Constituição de Atenas, encontrado nos anos 1880, nas areias do Egito (Hansen, 1991, p. 9). O correspondente material empírico que ele e seus alunos teriam reunido sobre 157 outras cidades-estado jamais apareceu. Mais recentemente, registros públicos importantes foram descobertos por escavações arqueológicas no século 20 (Ober, 2008, p. 73). Hansen (1992) afirmou, então, que o conhecimento moderno sobre a democracia antiga baseava-se mais em uma noção genérica das práticas da antiguidade do que nas especificidades atenienses. No entanto, alguns dos primeiros autores modernos
} 
- Em primeiro lugar, tinha algo a ver com a forma como um povo governava a si mesmo. Democracia envolvia alguma noção de autonomia. Nesse sentido, as análises sobre a democracia tendiam a invocar um segundo termo bastante complexo - "liberdade"10 - que Atenas utilizara tanto no sentido coletivo de estar livre de imposições externas, como no sentido da liberdade individual de não se estar submetido a outrem (Ostwald, 1995). Democracia tinha relação tanto com poder coletivo quanto com liberdade individual ${ }^{11}$.

- Em segundo lugar, democracia tinha alguma relação com o modo como um determinado território geográfico era governado. Para os atenienses, era a cidade-estado. No século 18, era o estado nacional. Esta noção se mantém. Poderíamos discorrer sobre o que significa uma família democrática, ou um local de trabalho democrático ou, ainda, uma universidade democrática. Porém, se demando a estudantes que citem democracias do mundo, eles começam indicando países.

Mas nem todo o povo no território constituía o povo autônomo. Isso conduz ao terceiro grande ensinamento dos exemplos antigos.

- Democracia era um sistema que incluía algumas pessoas com plenos direitos, os quais eram negados a outras. Aqueles que usufruíam plenos direitos eram:

- Adultos, não crianças ou adolescentes

\footnotetext{
pensavam em Atenas simplesmente como um exemplo particularmente significativo, vide Furetière (1970) quando afirmava que a democracia só floresceu nas repúblicas de Roma e de Atenas. Por ser Atenas, hoje, o exemplo mais bem compreendido e mais comumente evocado, algumas vezes utilizarei simplesmente "Atenas" para referir-me aos modelos antigos, ao invés de tentar entender em que contexto específico os autores do século 18 consideravam aquela cidade-estado comparativamente ao outros modelos genéricos.

10 "Liberdade" possui uma história complexa, de sentidos múltiplos e mutáveis (Patterson, 1991; Foner, 1998; Przeworski, 2003; Fischer, 2005).

${ }^{11}$ Ao revisar os estudos de autores clássicos, Ober (2008, p. 70) informa que o significado original de democracia era o de 'capacidade de um público, que consistia de homens adultos, de alcançar coisas de valor na esfera pública' - portanto, 'o povo com poder' ao invés de simplesmente 'o poder do povo'.
} 
- Homens, não mulheres

- Os livres, não os escravos

- Cidadãos, não estrangeiros.

A democracia, portanto, era um sistema de autogoverno de um território por algumas pessoas que detinham plenos direitos. Ao longo dos vários séculos passados, tem havido muita disputa quanto a quem de fato deveria deter plenos direitos e quem não. Após longas lutas, em múltiplas nações, já não aceitamos que eles caibam somente aos homens e não às mulheres, e somente às pessoas livres, não às escravizadas. As mulheres têm direitos políticos em todos os países que se afirmam democráticos e a escravidão já não é tolerada ${ }^{12}$. Por outro lado, ninguém hoje duvida de que eles valem para adultos, não para crianças. Em todo estado que se afirma democrático, no início do século 21, existe uma idade base para o usufruto de plenos direitos ${ }^{13}$. E, hoje, discutem-se, também, direitos de estrangeiros não cidadãos. Em resumo, duas das quatro grandes exclusões foram derrogadas ao longo dos últimos dois séculos, uma segue firme como sempre foi, e uma, como irei sustentar adiante, está começando a suscitar algumas questões interessantes.

- O quarto importante tema conhecido dos fundadores da democracia moderna era totalmente rejeitado por eles: a organização do governo na Antiguidade ${ }^{14}$. Para os europeus educados no século 18, a democracia ateniense possuía uma série de características notáveis.

\footnotetext{
${ }^{12}$ Sobre o fim da legalidade da escravidão, em muitos países em que ela ainda existia após a Segunda Guerra Mundial, ver Miers, 2003. Ativistas de direitos humanos têm plena consciência de que, apesar de ilegal, a escravidão segue existindo e vitima, conforme uma das estimativas, cerca de 27 milhões de pessoas (Bales, 2004, p. 4).

${ }^{13}$ As análises sobre a democracia têm dedicado muito menos atenção à exclusão das crianças do que a questões envolvendo gênero, liberdade/escravidão e nacionalidade. Porém, ver Earls (2011). ${ }^{14}$ Os modelos de governo da Antiguidade mostraram-se mais pertinentes mais tarde, do que o eram no momento da implantação da democracia moderna. A intensidade da participação dos atenienses na vida política veio a mostrar-se válida para os Americanos de final do século 20 desapontados com os baixos índices de envolvimento (Hansen, 2005, p. 2-24)
} 
1. Eles sabiam que democracia significava seleção por sorteio para a maior parte dos cargos, com mandatos bastante limitados.

2. Sabiam que havia eleições para alguns cargos, mas que este era um ponto de menor relevância no governo ateniense.

3. Sabiam que algumas decisões eram tomadas em assembleias de todos os cidadãos, inclusive decisões de grande impacto, como a de entrar em guerra.

4. Sabiam que qualquer pessoa, independentemente de seu poder, poderia ser exilada, por decisão do voto dos cidadãos.

Uma vez que cargos importantes eram escolhidos por sorteio e outras decisões eram tomadas pelos cidadãos em assembleia, eleições eram muito menos importantes em Atenas do que o são para a forma como concebemos democracia hoje. Esta é uma das razões por que a primeira geração de democratas modernos não considerava as disputas eleitorais entre partidos políticos essenciais para a democracia e tendiam, na verdade, a desprezá-las. Os democratas do século 18 jamais poderiam imaginar que os cientistas políticos da atualidade viriam a considerar disputas eleitorais entre partidos como um dos traços definidores da democracia $^{15}$. Por outro lado, não lhes era de todo inimaginável conceber a democracia sem direitos políticos para as mulheres. Certamente, era tão fácil concebê-la assim, que um traço saliente dos estados europeus que se democratizaram na era da revolução, bem como dos novos estados das Américas, muitos com significativos atributos democráticos, era o de que todos deixavam de fora as mulheres. E não era vedado imaginar ci-

\footnotetext{
${ }^{15}$ Para alguns, o fato de que o poder pode mudar de mãos como resultado de eleições é o atributo que define a democracia moderna, uma perspectiva influenciada por Schumpeter (1943, p. 269), que o definiu como o arranjo institucional para se alcançar decisões políticas, no qual os indivíduos obtêm o poder de decidir, por meio de uma disputa, a vontade do povo. Para uma defesa recente dessa definição eleitoral "minimalista" de democracia, ver Przeworski et al. (2000).
} 
dadania democrática para alguns coexistindo com a escravidão de outros. Modelos antigos não só destacavam a escravidão, como, na perspectiva de alguns autores, esta representava um fundamento crucial sobre o qual se apoiara a antiga democracia o que, portanto, também justificava a escravidão no contexto da democracia moderna ${ }^{16}$.

O quinto elemento importante conhecido no século 18 sobre o passado distante era o de que o mundo antigo possuía uma cultura política digna de imitação (Parker, 1965). Em seus bons momentos ${ }^{17}$, cidadãos com espírito público treinavam-se nas artes da retórica para os debates sistemáticos que precediam as decisões coletivas. Uma cultura democrática centraria a política na persuasão exercida entre cidadãos iguais com vistas ao bem comum, ao invés de baseá-la na submissão de subordinados por meio da violência visando aos interesses próprios dos poderosos. A história antiga foi rastreada em busca de episódios em que o auto-interesse ficava em segundo plano em relação ao interesse público e sacrifício pessoal. Não só tais virtudes eram vistas como admiráveis, mas também as culturas políticas antigas pareciam modelar a própria ideia de emulação de modelos meritórios, quando jovens cidadãos buscavam conquistar respeito seguindo os exemplos de reconhecidos predecessores. Direitos substanciais para os cidadãos eram acompanhados de significativas responsabilidades relativas aos fins públicos ${ }^{18}$.

\footnotetext{
${ }^{16}$ Sobre a invocação de "liberdade" e de "democracia" por ambas os movimentos pro e contra a escravidão que antecederam a guerra civil norte-americana, ver Fischer (2005, p. 274-354).

${ }^{17}$ Democracia era considerada como tendo muitos maus momentos enquanto um campo fértil para sublevação, conflito e anarquia, e, no século 18, tinha grandes chances de ser vista, em essência, como negativa, embora proveitosa quando pequenas doses eram combinadas à monarquia e à aristocracia em um louvado governo "misto".

${ }^{18} \mathrm{Em}$ outros aspectos, também, os autores do século 18 (pelo menos, os de línguas francesa e inglesa) estavam mais inclinados a procurar modelos romanos a gregos, mais os de Esparta que de Atenas, mais os de apelo semi-mítico sobre as origens da democracia ateniense do que os das reais instituições da época de Péricles. A evolução dos estudos reverteu as atenções para Atenas nos séculos 19 e 20 (Hansen, 1992).
} 


\section{A democracia é dinâmica}

O que sugere este pequeno trecho histórico? Que uma boa parte daquilo que consideramos democracia, seja em relação a quem ela inclui e quem não, seja no modo como aqueles que têm poder são escolhidos, mudou muitíssimo desde os anos 1780. Às vezes falamos como se soubéssemos o que é democracia, mas o que ela é muda à medida que as pessoas desenvolvem diferentes concepções do que significa ser um povo autônomo ou de quais habitantes de um determinado território devem participar plenamente.

Não tem sido incomum, por exemplo, pessoas afirmarem que se governam democraticamente e, ainda assim, negarem radicalmente a outras o direito de participação. Tampouco tem sido incomum que uma tal exclusão seja contestada, às vezes de forma exitosa e, às vezes, em nome da democracia. Aqui apresentamos dois exemplos do século 19 - o primeiro da África e o segundo da Índia. Quando habitantes de língua holandesa do sul da África se deslocaram para o norte, para escapar ao governo britânico, eles fundaram pequenas repúblicas que foram qualificadas por um importante estudioso da democracia, James Bryce, como alguns dos lugares mais democráticos do planeta ${ }^{19}$. É muito interessante ler Bryce, hoje, descrevendo aquelas repúblicas bôer, em que os recém-chegados facilmente adquiriam direitos e nas quais os homens adultos participavam como iguais. Homens brancos, diga-se. Os africanos, que lá estavam antes, não possuíam nenhum direito nessas repúblicas democráticas.

Como um segundo exemplo, podemos trazer John Stuart Mill, conhecido como o grande defensor do autogoverno, das liberdades individuais e dos direitos das mulheres. Ele se indignava ante a negação de autonomia para algumas colônias britânicas. Mas Mill também considera-

\footnotetext{
${ }^{19}$ Para Bryce (1891, v.1, p. 380), elas eram altamente democráticas e uma delas constituía mesmo uma comunidade autônoma ideal (Bryce, 1899, p. 314).
} 
va a autonomia totalmente inapropriada para grandes números de seres humanos de pele escura que viviam sob as leis britânicas, particularmente para os indianos, os quais ele considerava incapazes de governarem-se adequadamente. Conforme ele mesmo coloca em "On Liberty" (Mill, 2003, p. 81), o [d]espotismo é um modo legítimo de governo em se tratando de povos bárbaros, desde que o fim seja seu aprimoramento e os meios se justifiquem pela realização efetiva desse fim.

Evidentemente, no século 21, muitos sustentariam que a luta dos africanos pela conquista de direitos democráticos na África do Sul ou a dos indianos por governarem-se autonomamente constituíram avanços significativos da democracia, o que significa dizer que tendemos a concordar com noções consideravelmente mais inclusivas do que deve ser democracia. Isto nos faz recordar que aquilo que temos considerado democracia sofreu enorme transformação.

A democracia parece ser intrinsecamente dinâmica, porque cria movimentos sociais encorajados pela frustração com o caráter pouco democrático da prática das instituições, incluindo-se aí os limites de inclusão e exclusão; porque seus vários postulados são, com frequência, contraditórios, possibilitando a diversos movimentos reivindicarem a bandeira democrática; porque os detentores do poder consideram útil afirmar que os arranjos políticos que os sustentam no comando são "democráticos", por menos equitativos e mais opressivos que possam ser; e porque movimentos antidemocráticos são criados juntamente com os movimentos em defesa de perspectivas democráticas alternativas (Markoff, 2011). Não há razão para acreditar que a noção de democracia a prevalecer daqui a dois séculos será a mesma hoje vigente, assim como nosso entendimento atual de democracia não é o mesmo de quando as revoluções sociais criaram novas instituições há pouco mais de dois séculos. A despeito de toda a transformação no decorrer desses séculos, a fórmula de democracia como um composto de um povo com governo autônomo em um terri- 
tório demarcado ainda parece ser fundamental. Democracia refere-se à governança de nossa limitada unidade, o estado nacional. Hoje, começase a questionar seriamente se é isso que democracia deve continuar significando.

\section{Desafios do século 21 à democracia nacional}

Duas características da ordem global do início do século 21 suscitam questões relevantes sobre se podemos continuar concebendo democracia principalmente como um atributo de estados nacionais independentes. A primeira dessas características é a criação e fortalecimento, ainda em curso, de instituições de governança transnacional. Algo que já nos brindou com estruturas como as Nações Unidas, a União Europeia, a Organização Mundial de Comércio, o Fundo Monetário Internacional e o Banco Mundial. Na medida em que essas instituições sejam efetivas, elas impõem sérias limitações aos estados nacionais. Mas a gravidade de alguns dos problemas da ordem mundial torna provável que essas instituições, ou outras novas, serão fortalecidas e, com esse fortalecimento, trarão desafios à democracia dos estados nacionais.

A segunda característica importante dos estados nacionais é a enorme disparidade de riqueza e poder entre eles - alguns com muito mais capacidade do que outros de realizar seus projetos -, inclusive diferenças nas condições de terem seus projetos apoiados pelas instituições de governança transnacional. Isto tomado em conjunto, afigura-se muito provável questionar-se, de forma crescente, se os significados de democracia se esgotam nos modos de governança de estados individuais. Em outras palavras, se ainda seremos capazes de aferir a situação de democracia sem inquirir sobre o que significa um mundo mais democrático, não só sobre avanços da democracia dos estados nacionais. 
As duas questões estão interconectadas, porque os estados ricos e poderosos têm um peso significativo dentro das organizações transnacionais instituídas ${ }^{20}$, mas, mesmo sem essa dimensão, a própria existência de organismos transnacionais efetivos coloca desafios à nossa concepção de democracia. Tais desafios vão adquirir crescente relevância, pois há uma série de temas bastante sérios em escala global que, por certo, irão forçar a criação de novas instituições transnacionais.

Vou centrar-me, aqui, em um conjunto de questões colocadas pelo mundo interconectado da atualidade, em que muitas coisas fluem através das fronteiras nacionais... mercadorias, investimentos, imagens de TV, ideias sobre a gestão das economias, trabalhadores migrantes, refugiados, armas, terroristas, narcóticos, microorganismos infecciosos, gases de efeito estufa, e ativistas de movimentos sociais. Podemos indagar-nos se alguma das noções centrais que o século 18 tomou emprestadas de Atenas ainda fazem sentido; particularmente, a ideia chave de que um povo pode autogovernar-se em um território nacional.

No início do século 21, os estados nacionais estão seriamente ameaçados por uma variedade de problemas muito graves, alguns dos quais põem em risco uma existência humana digna. Soluções para esses problemas constituirão desafios importantes às políticas democráticas, em parte, porque serão profundamente polêmicos no âmbito dos estados nacionais, inclusive nos mais democráticos dentre esses; e, em parte, porque qualquer solução irá envolver a criação de agências transnacionais efetivas, as quais estarão ameaçando a democracia até então alcançada pelos estados. Aqui está uma pequena lista de grandes problemas:

\footnotetext{
${ }^{20}$ Isto confere importância à questão de se essas organizações podem ser democratizadas. Para uma análise perspicaz da ONU, ver Smith (2008). A comparação da dominação do Banco Mundial pelos estados ricos e poderosos (George, 1994) com uma maior independência da Organização Mundial de Saúde (Chorev, 2012) revela que precisamos entender as particularidades das organizações transnacionais ao avaliar as perspectivas - e as estratégias de desenvolvimento - de um mundo mais democrático.
} 
1. a probabilidade de epidemias globais letais disseminarem-se tão facilmente quanto o permitam as tarifas aéreas promocionais. Há poucos anos atrás, o mundo foi aterrorizado pela possibilidade de o vírus da gripe aviária desenvolver a capacidade de migrar entre humanos. Outros temem que a próxima enfermidade que, como a Aids, se transmita de animais para seres humanos possa ser muito mais facilmente contraída e de letalidade mais acelerada. Prontamente, evocamos a boa sorte de que o vírus da gripe $\mathrm{H} 1 \mathrm{~N} 1$, de 2009, não tenha sido tão letal quanto poderia.

2. Criminalidade transnacionalizada, tráfico de drogas, de armas e, mesmo, de seres humanos arruínam a vida pública de países inteiros ${ }^{21}$.

3. Proliferação nuclear, com probabilidade de, cedo ou tarde, significar armas de destruição em massa nas mãos de criminosos, terroristas, estados vingativos ou de dementes endinheirados.

4. Ameaça de desajustes econômicos com rápido fluxo de investimentos de um lugar para outro. Apesar de toda a atenção dada a esta questão, desde a crise financeira em curso, iniciada em 2008, as democracias ricas do mundo parecem não ter pressa em implantar barreiras eficazes, sem as quais haverá seguramente uma próxima.

5. Se algo já houve a exigir ação transnacional coordenada, este algo são as alterações climáticas globais. Não há, contudo, qualquer sinal de que uma tal ação venha a ocorrer em um futuro próximo e muitas razões para duvidar que ocorra.

6. Algumas dessas questões são exacerbadas pela propensão do capitalismo globalizado a desenvolver e empregar, em sua busca implacá-

${ }^{21}$ Para dúvidas sobre a extensão da criminalidade transnacionalmente coordenada, ver Collins (2009). Porém, coordenados ou não, os fluxos ilícitos transnacionais têm consequências gigantescas. 
vel pelo lucro, novas tecnologias que podem ter consequências destrutivas de grande alcance, cujos exemplos podemos ver na destruição das tradições agrárias, por meio de monoculturas industrializadas, ou na busca imprudente por petróleo no fundo dos oceanos. Ambos os exemplos suscitam sérias dúvidas sobre a capacidade da democracia mais poderosa da atualidade de lidar com problemas globais, uma vez que o primeiro tem sido ativamente promovido pelo apoio dos EUA a empresas agroindustriais e o segundo envolveu conivência entre $\mathrm{O}$ aparato regulatório do estado e as empresas petrolíferas ${ }^{22}$.

7. Finalmente, consideremos os fluxos transnacionais de pessoas, os quais têm colocado questões muito polêmicas tanto no âmbito das democracias ricas como em outros. Havendo países mais pobres lado a lado com outros mais ricos, lugares mais pacíficos acessíveis a partir de locais onde as vidas estão ameaçadas por indizível violência, e com os países mais ricos enfrentando baixas taxas de natalidade e populações mais idosas e enfermas, não há o que impeça pessoas de fugirem da pobreza e da violência rumo à Europa ocidental, aos EUA ou ao Japão, trazendo, com isso, problemas étnicos, culturais e outros que, por si sós, desafiam os significados de democracia e suscitam novas questões sobre inclusão e exclusão. Discute-se hoje, por toda a Europa ocidental, se preservar as democracias europeias significa excluir aqueles considerados diferentes e, algumas vezes, deficientes em valores democráticos, ou incluí-los à

\footnotetext{
${ }^{22}$ Erik Olin Wright (2010, p. 69) explica, sucintamente, que recursos naturais não renováveis são sistematicamente subprecificados no mercado, uma vez que seu valor para os povos do futuro não é registrado nas dinâmicas de oferta e demanda do presente. O resultado é que atores em mercados capitalistas superconsomem esses recursos. Mercados capitalistas são intrinsecamente organizados segundo horizontes de tempo relativamente curtos e, sendo assim, a única forma de fazer com que o valor desses recursos para as futuras gerações seja levado em conta nas decisões sobre o uso presente dos mesmos é impondo restrições ao capitalismo, novamente, por parte do estado ou de forças sociais organizadas.
} 
força de adesão a concepções universalistas de cidadania. A interconexão entre exclusão e inclusão constitui, uma vez mais, um tema central dos debates nas democracias ricas ${ }^{23}$.

Somada a temores associados à violência, a simultaneidade desses vários problemas fez com que as preocupações com segurança se tornassem onipresentes, em uma mescla de medos de terroristas, de criminosos, de imigrantes e da perda do emprego ${ }^{24}$. Quando as democracias ricas fortalecem seus aparatos de segurança interna, emerge uma série de ameaças às suas próprias democracias nacionais. Os Estados Unidos, por exemplo, estão agora envolvidos em episódios de tortura e procedimentos judiciais que há poucos anos atrás seriam denunciados como antidemocráticos por todo o país (Cole; Lobel, 2007).

Podemos observar que alguns desses problemas já estão ameaçando o governo democrático. Por exemplo, o comércio internacional de substâncias psicoativas tem tido um impacto extremamente nefasto no contexto da recente abertura democrática do México. O enfraquecimento do presidente do México em relação ao congresso e o do governo central em relação aos estados - por mais desejáveis que essas mudanças possam ser na perspectiva de teóricos da democracia - facilitam muito

\footnotetext{
${ }^{23}$ No primeiro turno das eleições presidenciais da França, em abril de 2012, em meio à crise econômica europeia, a campanha da Frente Nacional centrou-se nas restrições à imigração para proteger empregos, e alcançou 18\% dos votos. Esperando conquistar o apoio desses mesmos eleitores no segundo turno, o candidato e então presidente Nicolas Sarkozy afirmou que preservar nosso modo de vida é fundamental para esta eleição (Boxell; Daneshkhu, 2012).

${ }^{24}$ Os debates em torno de uma legislação restritiva nos Estados Unidos, ao final da primeira década do século 21, incluíam temores frequentes de que os imigrantes ilegais estivessem transportando drogas para os narcotraficantes e de que iriam competir por postos de trabalho em um momento de desemprego em alta. Um membro do Congresso americano expressou o temor de que os filhos de imigrantes ilegais nascidos nos EUA - e, portanto, cidadãos americanos - fossem criados por terroristas no país de seus pais e regressassem, adultos, com passaportes válidos, para executar missões perversas (Kleefeld, 2010); outro congressista afirmou que o Hezbollah estaria aliado a cartéis de drogas para planejar ações terroristas nos EUA (Elliot, 2010).
} 
aos comandantes do narcotráfico afirmarem-se com violência em uma escala assustadora ${ }^{25}$. Este problema ilustra, também, o desafio a noções de democracia limitadas a estados nacionais isoladamente. Os cidadãos mexicanos não têm qualquer influência sobre as políticas de drogas dos EUA, tampouco sobre legislação de armas; no entanto, a demanda de narcóticos dos EUA, a "Guerra contra as Drogas" do governo americano e as armas oriundas desse mesmo país têm resultado em graves consequências para os mexicanos.

Mas, mirando adiante, destaca-se uma questão maior. É possível que a ameaça de epidemias ou de desastres nucleares, ou o avanço dos oceanos, cedo ou tarde, evocarão organismos transnacionais de tomada de decisão com poder de imposição. Essas são ameaças colocadas tanto às nações ricas como às mais pobres, e tanto às pessoas ricas como aos pobres. Alguns desses problemas, de artefatos nucleares à mudança climática, constituem sérias ameaças a uma existência humana digna e políticas de imigração eficazes escapam aos governos em toda a parte. O contínuo fracasso dos governos democráticos em administrar tais problemas de forma efetiva pode, como já ocorreu nos anos 1930, estimular movimentos antidemocráticos. Se as democracias mostrarem-se insuficientes, as pessoas podem voltar-se para outras alternativas ${ }^{26}$. Contudo, a preocupação mais grave é que mesmo um prognóstico otimista sugere futuras ameaças à democracia na forma como ela é hoje praticada. Se, cedo ou tarde, ações efetivas serão adotadas para lidar com esses riscos globais, a criação já em curso de instituições transnacionais atuantes suscitará questiona-

\footnotetext{
${ }^{25}$ Para um levantamento sobre estas questões, ver Bergman e Whitehead (2009).

${ }^{26}$ No momento em que se produz este texto, algumas das democracias ricas têm se destacado mais por gerar movimentos por renovação democrática do que outros antidemocráticos, em resposta ao fracasso dos detentores do poder de lidar com crise econômica iniciada em 2008. As consequências políticas da Grande Recessão têm sido bem diferentes daquelas da Grande Depressão, um tópico importante que necessita análise aprofundada.
} 
mentos sobre o significado de democracia nacional. Se a omissão em administrar tais problemas pode levar governos democráticos ao descrédito, o sucesso pode ameaçá-los, também. Seguirá a democracia sendo vista basicamente como uma forma de governo de estados nacionais isolados?

Costuma ser um tanto arriscado especular sobre mudanças radicais nos modos de pensar. Mas sabemos que democracia tem sido objeto de significativa reconsideração desde o final do século 18, com sérios questionamentos dos modos como são definidos os que fazem jus a plenos direitos. A crescente estruturação de espaços transnacionais de tomada de decisão com pouca responsabilidade perante os afetados por tais decisões parece tendente a colocar em questão a suficiência da noção central de um povo autônomo em um território delimitado. Em vários lugares, as pessoas podem perguntar-se o que significa democracia, se o FMI possui, de certa forma, mais impacto sobre a vida cotidiana do que, digamos, o governo do país em que elas vivem. Mesmo na UE, cujas instituições têm um caráter muito mais democrático do que o FMI ou a OMC, é comum falar do duplo déficit democrático; duplo, porque a UE é um caso menos democrático do que os estados membros que a compõem, mas, também, porque, na medida em que as novas leis dos estados membros são meras especificações nacionais das normas da UE, o grau de responsabilização democrática no âmbito dos estados membros decresce ${ }^{27}$.

Durante a campanha para eleições nacionais de 2011, muitas pessoas na Espanha, um dos lugares em que, na década de 1970, pôs-se em marcha a grande onda de democratização, vivenciaram com desalento a probabilidade de que escolher entre os principais partidos da esquerda e da direita não faria qualquer diferença relevante nas políticas do governo para lidar com sua parte na crise econômica em curso na Europa. Pouco

\footnotetext{
${ }^{27}$ Para uma amostra da extensa literatura sobre UE e democracia, ver Smith e Wright (1999).
} 
antes da eleição, dezenas de milhares de pessoas deram início ao que se tornou o Movimento 15 de Maio, que ocupou praças públicas por várias semanas em dezenas de cidades espanholas, questionando o processo eleitoral em sua forma instituída, e defendendo uma "democracia real". Por toda a Espanha, podiam-se ler cartazes dizendo Eles não nos representam (Artal, 2011). Poucos meses depois, os trabalhos da Eurozone levaram à indicação de economistas para chefiar os governos da Grécia e da Itália, na esperança de aplacar as instituições financeiras europeias e seu estado mais poderoso, a Alemanha. Italianos e gregos viram-se questionando a significância da democracia de seu país ${ }^{28}$.

Instituições transnacionais já desafiam a concepção fundamental de que democracia diz respeito ao governo autônomo de um certo povo em um determinado território; o fortalecimento das instituições transnacionais só fará ampliar este questionamento. Desde o século 18, a noção de que um povo autônomo em um território delimitado pudesse existir tem sido fundamental Instituições democráticas nacionais seriam uma forma de possibilitar isso. Os movimentos democráticos teriam como objetivo a criação dessas instituições. Assim, as pessoas lutavam por coisas como responsabilização dos governos perante os parlamentos; sufrágio mais amplo, de modo a que aqueles com plenos direitos representassem um número mais próximo do de toda a população; direitos individuais que os estados não pudessem infringir, incluindo a liberdade de defender políticas e de formar partidos; apuração honesta das votações, de modo a que a decisão comum reflita as reais decisões individuais dos cidadãos; e mais.

\footnotetext{
${ }^{28}$ Embora a afirmação de que os Occupy Movements (Movimentos de Ocupação) dos EUA partilhavam vários aspectos com os protestos europeus, ao declararem que somos os 99\% cujas vozes não são ouvidas, entre os manifestantes americanos não foi comum estabeleceremse conexões com os processos transnacionais (Smith, 2012). Se os argumentos deste artigo estão corretos, veremos mais dessas conexões serem estabelecidas no futuro, talvez algo como o Fórum Social dos EUA, o ramo norte-americano do processo de Fórum Social Mundial (Smith; Reese; Byrd; Smythe, 2011).
} 
Durante boa parte dos dois séculos e quarto decorridos desde que o big bang revolucionário de finais do século 18 inaugurou a história moderna da democracia nacional, a hegemonia imperial europeia significava que, para uma parcela importante da população mundial, a noção básica de povo autônomo em um território nacional não era algo realizável ${ }^{29}$. Porém, com o fim do império europeu, na geração posterior à Segunda Guerra Mundial, a democracia passou a ser pelo menos imaginável para todos e a questão central parecia ser a da construção das instituições certas para realizá-la, em cada estado. A democratização do mundo poderia ser imaginada como consistindo da democratização dos estados individualmente. Contudo, esta dupla conquista - primeiro, a descolonização e, depois, a onda democrática geograficamente mais extensa da história - colocou em relevo os limites da democracia regional, pois falta aos estados nacionais a capacidade para resolver os problemas transnacionais cada vez mais evidentes enfrentados pela humanidade e prevalece uma desigualdade extrema de riqueza e poder entre os estados.

Não só a emergência de problemas globais potencialmente catastróficos e o provável fortalecimento de instituições transnacionais levarão a um repensar a democracia; também essas grandes disparidades de riqueza e poder o farão. Quando as pessoas na Europa mediterrânea, por exemplo, se perguntavam, em 2011 e depois, se ainda faz sentido falar de democracia nacional, não é simplesmente em razão da importância de instituições transnacionais como a UE, mas também em razão do peso, no âmbito da UE, de sua potência econômica, a Alemanha.

\footnotetext{
${ }^{29} \mathrm{O}$ entrelaçamento de democratização de alguns dos estados ricos com a expansão de seu governo imperial nos séculos 19 e 20 é uma grande questão a merecer tratamento aprofundado. A maioria das pessoas sob governo britânico, francês, holandês ou belga, quando aqueles países se democratizaram, não tinham qualquer possibilidade de inclusão (Clark, 1936, p. 23)
} 
Nos anos 1970, o regime colonial havia praticamente acabado. Isto não só abriu caminho para a grande onda mundial de democratização, mas também criou condições para o que podemos chamar de grande desilusão - a descoberta de que democracia nacional não é o mesmo que real autonomia. Para países africanos que tentam negociar os termos do comércio agrícola com um estado protecionista da Europa ocidental e para países latino-americanos que tentam negociar os termos do comércio agrícola com os protecionistas Estados Unidos, pode não parecer de todo óbvio que as condições fundamentais de vida estão sob o controle de governos comprometidos com a democracia, mesmo em épocas e lugares em que os governos atendem aos critérios democráticos convencionais. Assim, as grandes disparidades de riqueza e poder entre os estados apontam como mais um desafio à persistência do sentido de democracia nacional. Recentemente, os gregos têm se referido ao presidente dos EUA como o planetarca (planetarch) ${ }^{30}$, talvez outro termo político útil oriundo de um lugar que há muito tempo atrás nos presenteou com tantos. Este fato pode ser visto como sintomático da sensação, por parte dos cidadãos, de que seu governo não é plenamente soberano.

O trabalho de Immanuel Wallerstein (p.ex., 2004) parecia sugerir enfaticamente que, de um certo modo, não há nada de novo aqui, que a noção de um povo autônomo em um território delimitado tem sido, há meio milênio, uma falácia, pois a rede de interconexões econômicas significativas sempre teve uma escala geográfica muito maior do que a geografia do controle político. Certamente, um dos fortes mecanismos de reprodução do sistema-mundo capitalista tem sido o fato de que as lutas políticas desenrolam-se no âmbito de influência dos estados nacionais. Isto limita a capacidade, mesmo dos movimentos sociais, de assumir

\footnotetext{
${ }^{30} \mathrm{O}$ uso desse termo será objeto de um ensaio a ser publicado por Mike-Frank Epitropoulos e por mim.
} 
o controle das circunstâncias que conformam as vidas das pessoas, pois algumas dessas circunstâncias, principalmente a divisão do trabalho em uma economia transnacional, estão estruturadas em uma escala muito mais ampla ${ }^{31}$. Porém, o que parece ser novo em nosso momento histórico é a consciência disseminada de que os estados nacionais são instrumentos insuficientes para lidar com os problemas críticos enfrentados hoje pela humanidade. Isto, para voltar ao nosso ponto central, começa a pôr em questão a validade do pressuposto de que pode existir um povo autônomo em um território delimitado ${ }^{32}$. Este conjunto de questões só irá evoluir caso existam mecanismos transnacionais efetivos para lidar com alguns desses problemas transnacionais, porque a própria eficácia de tais mecanismos colocará em questão, de modo ainda mais acentuado, a efetividade dos estados autônomos.

Assim como o século 18 podia imaginar democracia com escravos e sem mulheres, mas tinha dificuldade em concebê-la sem os pobres, para apontar novamente a percepção de Atenas prevalente à época, era comum referir-se a lugares como democráticos, na medida em que suas instituições políticas incorporassem os pobres embora sem dar atenção a outras formas de exclusão. Encontramos nada menos que um estudioso, e profeta, da democracia como Tocqueville (1994, v. 1, p. 57, 197, $199,200)$ maravilhado com o que ele repetidamente chamava de sufrágio universal alcançado pelos americanos, em uma época em que nenhuma mulher e só um pequeno número de negros livres podiam votar. Sufrágio universal, certamente, acaba sendo um conceito curiosamente errôneo,

\footnotetext{
${ }^{31}$ Outras circunstâncias importantes desenrolam-se em uma escala muito menor. Não abordo, aqui, algumas questões muito importantes sobre o papel das arenas locais em reconceber a democracia.

${ }^{32}$ Deixo de lado, aqui, a questão importantíssima de como a noção ainda mais fundamental de "o povo", como um ator coletivo unitário, moldou a ideia de democracia. Pierre Rosanvallon (1998) intitula sua absorvente história da representação democrática na França do século 19 como "O povo inencontrável" (Le Peuple Introuvable).
} 
forte evidência do grau em que o apelo de inclusão universal, elemento tão significativo da legitimação democrática, é sempre uma ficção. Não só quando era usado pelos mais sagazes estudiosos da democracia, em um momento em que as noções do século 21 sobre quem se encaixa neste universo não estavam ainda concebidas, mas é sempre uma ficção, pois, até hoje, nenhum estado democrático rompeu com o princípio ateniense de negar plenos direitos ativos às crianças e todos os estados democráticos fazem distinção entre os direitos de não-cidadãos e os daqueles que têm cidadania plena. Em nossa era, contudo, a questão dos análogos atuais da exclusão ateniense dos não-atenienses começa a ser desafiada ${ }^{33}$. A cidadania nos estados nacionais não só não é suficiente para promover direitos universais, como a própria divisão de pessoas segundo distintas cidadanias é um dos principais mecanismos para a desigualdade social considerada em escala planetária, como estamos começando a visualizar ${ }^{34}$. A cidadania em estados nacionais é um mecanismo básico de sustentação da desigualdade global e, mesmo que houvesse cidadania democrática em toda a parte, algo que está muito longe de ser verdade, esta característica dos direitos de cidadania ainda não seria alterada. Cidadania e democracia seguem sendo um misto de inclusão e exclusão.

O ponto conceitual importante é que a noção de democracia, adotada desde o final do século 18 até agora - referida, sejam quais forem seus outros significados, a um sistema de autogoverno de um determinado povo em um determinado território -, pode sofrer uma reformulação, em parte devido à crescente presença de instituições transnacionais que possivelmente irão expandir-se, e, em parte, porque a grande disparidade de

\footnotetext{
${ }^{33}$ Vale observar, porém, uma certa dissipação desta fronteira; na UE, os cidadãos de qualquer estado membro podem votar nas eleições da UE e em eleições municipais das cidades em que residem, ainda que não tenham cidadania daquele país.

${ }^{34}$ Para uma análise e evidências relevantes, ver Korzeniewicz e Moran (2009).
} 
riqueza e poder faz com que a afirmação de autonomia em alguns lugares pareça limitada ou mesmo falsa. Os dois questionamentos a uma noção formulada exclusivamente em termos de democracia nacional operam frequentemente juntos, porque essas instituições transnacionais constituem um dos principais loci onde se evidencia o poder desigual dos estados.

\section{Democracia para além dos Estados?}

É possível democracia em uma escala que transcenda o estado nacional? Esta é uma grande questão, para a qual não há resposta óbvia.

- Alguns diriam que não, porque a escala é grande demais para imaginar-se um governo em âmbito transnacional que efetivamente se reporte a algum organismo de cidadãos. Já no início do século 20, Max Weber considerava que o aparelho burocrático do estado moderno era extremamente resistente à supervisão efetiva pelos parlamentos eleitos e, por isso, ele tinha uma visão extremamente cética da possibilidade de um envolvimento popular no governo. Uma visão mais otimista é expressa por John Keane (2009, p. xxvi-xxvii) quem afirma que, por vários séculos, experimentamos o crescimento de novas formas de monitoramento e controle públicos do exercício do poder, algo que ele chama de democracia monitorada. Estreitamente relacionadas a esta, são a análise de Erik Olin Wright (2010, p. 145) da capacidade das pessoas de formarem associações para promover seus objetivos coletivos e sua defesa da factibilidade de se desenvolverem mecanismos fundados na vida social para moldar as ações do estado de modo a voltá-las a fins democráticos. Podemos acrescentar que, apesar dos esforços de autores das constituições do século 18 para limitar o papel político da maior parte dos cidadãos ao fato de serem eleitores, desde sua estreia revolucionária no século 18, a democracia nacional moderna tem sido um campo fértil para movimentos sociais (Markoff, 2011). 
- Outros diriam que não, porque as enormes diferenças entre culturas nacionais significam que a coexistência democrática não é possível. Como contra-argumento, pode-se considerar as enormes diferenças entre as culturas presentes quando da fundação dos Estados Unidos (Fischer, 1989), embora seja preciso ter em conta, também, que o desenvolvimento das instituições democráticas daquele país passou por muitas lutas, inclusive guerra civil.

- Outros mais diriam que não, porque as débeis identidades transnacionais tornam improvável a existência de um apoio generalizado à partilha de riscos e obrigações com aqueles tidos como diferentes. As solidariedades associadas a idealidas peculiaridades nacionais, nessa perspectiva, parecem mais fortes do que aquelas fundadas na humanidade compartilhada. Uma variante deste argumento adota o sentido de nação como o alicerce fundamental sobre o qual a ordem democrática pode erigir-se (Calhoun, 2007, p. 147-167). O contraargumento propõe que uma identidade comum pode emergir como resultado da submissão conjunta a uma mesma autoridade política. Isto parece sugerir que a construção de uma ordem autoritária transnacional pode ampliar as possibilidades de desenvolvimento posterior de uma ordem democrática, de modo análogo às histórias nacionais da Europa ocidental, onde, de um modo geral, os estados fortaleceram-se muito, antes de se tornarem mais democráticos (Tilly, 2004).

- Alguns, ainda, diriam que não, porque as democracias ricas atuais jamais aceitariam a diminuição e diluição radicais de seu poder, especialmente as mais poderosas entre elas. Não somente regimes despóticos resistem à autoridade de organismos judiciais transnacionais - basta considerar a ferrenha oposição dos Estados Unidos ao Tribunal Penal Internacional ${ }^{35}$. Embora os EUA desempenhem um

\footnotetext{
${ }^{35}$ Moravcsik (2000) explora essas questões de forma ampla.
} 
importante papel, quando se trata de formular normas para reger outros estados, o país resiste a submeter-se às mesmas ${ }^{36}$. Por outro lado, as democracias europeias ricas construíram a União Europeia e aceitaram alguma diluição de sua soberania.

- Por fim, alguns diriam que não, porque os muitos sistemas políticos cujo caráter democrático é muito limitado ou inexistente simplesmente jamais aceitariam incorporar-se a uma estrutura democrática mais ampla... ou a destruiriam se tentassem fazê-lo. Isto não significa apenas que regimes autoritários provavelmente resistiriam à sua incorporação em uma estrutura democrática, a qual poderia incentivar movimentos democráticos entre seus cidadãos; implica, também, que cidadãos de estados democráticos dificilmente ficariam satisfeitos com um arranjo que conferisse algum poder sobre eles a agentes de estados não democráticos. Mesmo nos estados membros da União Europeia, que constituem democracias pelos padrões de início do século $21^{37}$, há significativa oposição a expandir a autoridade daquele organismo, e uma das razões para isso é a percepção de que fazê-lo iria minar o significado da democracia alcançada pelos estados. Tanto mais para uma hipotética adesão de estados que incluíssem casos marcadamente autoritários.

Parece provável que o futuro próximo verá questões sérias serem levantadas sobre a validade do significado de democracia nacional em um mundo não democrático. Questões importantes poderão ser também suscitadas quanto à possibilidade de democracia fazer sentido em uma

\footnotetext{
${ }^{36}$ Como o coloca Ignatieff (2011): Desde Nuremberg, nenhum país investiu mais no desenvolvimento de jurisdição internacional para crimes de atrocidade e nenhum país trabalhou tão intensamente para assegurar que a legislação que propõe para os outros não se aplique a ele próprio. ${ }^{37}$ A nova constituição da Hungria, que entrou em vigor em 2012, pode fazer daquele país uma exceção (Dupré, 2012).
} 
escala mais ampla. Dizendo de outro modo, a emergência de instituições transnacionais e as persistentes disparidades de riqueza e poder entre os estados nacionais estão colocando em dúvida a noção fundamental de que democracia pode existir no âmbito daqueles estados nacionais isolados. Por outro lado, a ideia de que democracia possa ser construída para além dos estados não é nem um pouco óbvia. Recordemos, contudo, que, ao imaginar o que deve ser um estado mais democrático, os primeiros democratas da era moderna, fiéis ao modelo ateniense, romperam totalmente com o mesmo, em uma arena importante. Eles formularam instituições de governo totalmente novas. E, ao longo de dois séculos de lutas subsequentes, seus cidadãos seguiram ampliando largamente as fronteiras da inclusão na vida política nacional. Agora, é preciso mirar para além do estado nacional com a mesma criatividade.

Em outras palavras, estamos ingressando em uma era na qual o sentido de democracia, quando aplicado a um mundo em transformação, será provavelmente questionado, sem que haja uma resposta pronta. O que as pessoas pensam que significa democracia pode ser ainda válido, em parte, mas em parte já não satisfaz. Assim como ocorreu no século dezoito. O resultado do último questionamento é o que hoje chamamos de democracia. Na verdade, a reformulação já está em curso.

Há uma profusão de novas ideias. Alguns propõem uma reformulação mais ou menos radical de como alcançar uma democracia mais efetiva no âmbito dos estados nacionais; por exemplo, nas propostas de uma democracia deliberativa (p.ex., Fishkin; Laslett, 2003). Outros apontam fascinantes avanços em arenas locais (p.ex., Fung e Wright, 2003; Baiocchi, 2005). Alguns acadêmicos têm indagado o que poderia significar democracia para além do estado (p.ex., Archibugi; Held, 1995; Held, 1995; Morrison, 2004) e outros chamam a atenção para diferentes maneiras como os seres humanos têm organizado seus assuntos independen- 
temente do estado (Bamyeh, 2009). Cientistas políticos estão começando a analisar de que modo a hipótese de que o estado seria a arena relevante conformou séculos de discussão sobre a democracia até hoje (Goodhart, 2005). Pesquisadores dos movimentos sociais estão perscrutando os movimentos por um mundo mais democrático (p.ex., Smith, 2008; Smith et al., 2008; Evans, 2005). Muitos têm participado de movimentos que questionam a democracia em sua forma atual e propõem concepções democráticas alternativas; muitos outros têm assistido a isso com admiração ou aderido ao debate, na Espanha, nos EUA e em outros lugares. Um eminente sociólogo convidou-nos a refletir não só sobre que formas de existência social são desejáveis, mas, também, sobre quais formas de mudanças desejáveis são factíveis para desenvolver o que ele chama de uma teoria da transformação social emancipatória (Wright, 2010, p. 273-365). Teremos de questionar, além disso, que tipo de instituições poderão estimular uma renovação da imaginação política democrática. As instituições que reconfiguraram a democracia nacional nos séculos 18 e 19 - as escolas, a imprensa, os partidos, as organizações sindicais - poderão exercer esse papel no século 21? Ou teremos de criar novos espaços?

As pessoas podem começar a repensar a democracia fundamentalmente em razão da crescente influência do mundo exterior às fronteiras nacionais. Uma vez, comunidades de língua holandesa do sul da África pensaram estar criando sua própria democracia ao afastarem-se dos britânicos, e não viram necessidade de incluir africanos de pele escura. Democracia para nós, mas não necessariamente para eles [os outros], tem sido [uma característica] central à ideia de democracia, desde Atenas. A realidade global do século 21, porém, está tornando 'democracia para nós mas não para eles' algo difícil de conceber. Isto nos impele a questionar o que poderia significar um mundo mais democrático. 
Sociologias, Porto Alegre, ano 15, no 32, jan./abr. 2013, p. 18-50

\section{Referências}

ADAMS, Michael; LENNON, Mary Jane. Canadians, Too, Fault Their Political Institutions and Leaders, Public Perspective, v. 3, p. 19-21, Sep./Oct. 1992.

ARCHIBUGi, Daniel; HELD, David. (Eds.) Cosmopolitan Democracy. Cambridge, UK: Polity Press, 1995.

ARTAL, Rosa María. La energía liberada: El estallido social de un mundo en crisis. Madrid: Aguilar, 2011.

BAIOCCHI, Gianpaolo. Militants and Citizens: The Politics of Participatory Democracy in Porto Alegre. Stanford: Stanford University Press, 2005.

BALES, Kevin. New Slavery: A Reference Handbook. Santa Barbara, CA: ABCCLIO, 2004.

BAMYEH, Mohammed. Anarchy as Order: The History and Future of Civic Humanity. Lanham, MD: Rowman \& Littlefield, 2009.

BERGMAN, Marcelo; WHITEHEAD, Laurence. (Eds.) Criminality, Public Security, and the Challenge to Democracy in Latin America. Notre Dame: University of Notre Dame Press, 2009.

BRYCE, James. Studies in History and Jurisprudence. New York: Oxford University Press, 1901.

BRYCE, James. Impressions of South Africa. London: Macmillan, 1899.

BOXELL, James; DANESHKHU, Scheherezade. Sarkozy Seeks to Preserve Our Way of Life. Financial Times , Paris, online, 22 abr. 2012. Disponível em: <http://www.ft.com/intl/cms/s/0/496f2d5a-8cb9-11e1-9758-00144feab49a. html\#axzz2MdXwt1Uz>. Acesso em: 23 abr. 2012.

CALHOUN, Craig. Nations Matter: Culture, History, and the Cosmopolitan Dream. New York: Routledge, 2007.

CHOREV, Nitsan. The World Health Organization Between North and South. Ithaca, NY: Cornell University Press, 2012.

CLARK, Grover. The Balance Sheets of Imperialism: Facts and Figures on Colonies. New York: Russell and Russell, 1936.

CLARKE, Harold; JENSON, Jane; LEDUC, Lawrence; PAMMETT, Jon. Absent Mandate: Canadian Electoral Politics in an Era of Restructuring. Toronto: Gage, 1995.

COLE, David; LOBEL, Jules. Less Safe, Less Free: Why America Is Losing the War on Terror. New York: New Press, 2007. 
COLLINS, Randall. How Organized Is International Crime? Contemporary Sociology, Pennsylvania, v. 38, n. 6, p. 516-521, Nov. 2009.

COLLIER, David; LEVITSKY, Steven. Democracy with Adjectives: Conceptual Innovation in Comparative Research. World Politics, Cambridge, v. 49, n. 3, p. 430-451, Apr. 1997.

CONZE, Werner; KOSELLECK, Reinhart. (Eds.) Geschichtliche Grundbegriffe: Historisches Lexikon zur Politisch-Sozialen Sprache in Deutschland. Stuttgart: Klett Verlag, 1972-1984.

DALTON, Russell. Democratic Challenges, Democratic Choices: The Erosion of Political Support in Advanced Industrial Democracies. New York: Oxford University Press, 2004.

DIAMOND, Larry. The Spirit of Democracy: The Struggle to Build Free Societies Throughout the World. New York: Henry Holt. 2008.

DUNN, John. Setting the People Free: The Story of Democracy. London: Atlantic Books, 2005.

DUPRÉ, Catherine. Hungary's Fundamental Law Challenges the EU's Democratic Ideals. The Guardian online, 3 Mar. 2012. Disponível em: <http://www.guardian.co.uk/commentisfree/libertycentral/2012/mar/13/hungary-fundamental-laweu>. Acesso em: 23 Apr., 2012.

EARLS, Felton. (Ed.) The Child as Citizen: The Annals of the American Academy of Political and Social Science, v. 633, n. 1, Jan. 2011.

ELLIOT, Justin. GOP Rep: Hezbollah Partners with Drug Cartels to Infiltrate America's Southern Border. TPM Memo, 25 June 2010. Disponível em: <http:// tpmmuckraker.talkingpointsmemo.com/2010/06/gop_rep_hezbollah_is_infiltrating_americas_souther_1.php?ref=fpb>. Acesso em: 30 Apr. 2012

EVANS, Peter. Counterhegemonic Globalization: Transnational Social Movements in the Contemporary Global Political Economy. In: Janoski, Thomas; Alford, Robert; Hicks, Alexander; Schwartz, Mildred. The Handbook of Political Sociology: States, Civil Societies, and Globalization. Cambridge: Cambridge University Press, 2005. p. 655-670.

FISCHER, David Hackett. Liberty and Freedom: A Visual History of America's Founding Ideas. Oxford: Oxford University Press, 2005.

FISCHER, David Hackett. Albion's Seed: Four British Folkways in America. New York: Oxford University Press, 1989.

FONER, Eric. Story of American Freedom. New York: Norton, 1998.

FISHKIN, James; LASLETT, Peter. (Eds.) Debating Deliberative Democracy. Malden, MA: Blackwell, 2003. 
FUKUYAMA, Francis. The End of History? The National Interest, v. 16, p. 3-18, Summer 1989.

FUKUYAMA, Francis. The End of History and the Last Man. New York: Free Press, 1992.

FUNG, Archon; WRIGHT, Erik Olin. Deepening Democracy: Institutional Innovations in Empowered Participatory Governance. London: Verso, 2003.

FURETIÈRE, Antoine. Dictionnaire universel: contenant généralement tous les mots françois tant vieux que modernes, et les termes de toutes les sciences et des arts. Geneva: Slatkine Reprints, 1970.

GALLIE, Walter Bryce. Essentially Contested Concepts. Proceedings of the Aristotelian Society, New Series, v. 56, p. 167-198, 1956.

GEORGE, Susan. Faith and Credit: The World Bank's Secular Empire. Boulder: Westview Press, 1994.

GOODHART, Michael. Democracy as Human Rights: Freedom and Equality in the Age of Globalization. New York: Routledge, 2005.

HANSEN, Mogens Herman. The Athenian Democracy in the Age of Demosthenes: Structure, Principles and Ideology. Oxford: Blackwell, 1991.

HANSEN, Mogens Herman. The Tradition of the Athenian Democracy, AD 1750-1990. Greece and Rome, v. 39, n. 1, p. 14-30, 1992.

HANSEN, Mogens Herman. The Tradition of Ancient Greek Democracy and its Importance for Modern Democracy. Copenhagen: Royal Danish Academy of Sciences and Letter, 2005.

HANSON, Russell. The Democratic Imagination in America: Conversations with Our Past. Princeton: Princeton University Press, 1985.

HELD, David. Democracy and the global order: from the modern state to cosmopolitan governance. Cambridge: Polity Press, 1995.

HUNTINGTON, Samuel. The Third Wave: Democratization in the Late Twentieth Century. Norman, OK: University of Oklahoma Press, 1991.

IGNATIEFF, Michael. We're So Exceptional. New York Review of Books, v. 59, n. 6, Apr. 2012.

ISAKHAN, Benjamin; STOCKWELL, Steven. (Eds.) The Secret History of Democracy. London: Palgrave Macmillan, 2011.

KEANE, John. The Life and Death of Democracy. London: Simon and Schuster, 2009. 
KLEEFELD, Eric. Gohmert: There's a Diabolical 30-Year Plot to Have Terrorist Babies Born in U.S. TPM Memo, 26 June 2010. Disponível em: <http://tpmdc. talkingpointsmemo.com/2010/06/gohmert-theres-a-diabolical-30-year-plot-tohave-terrorist-babies-born-in-us-video.php?ref=fpb>. Acesso em: 23 Apr. 2012.

KORZENIEWICZ, Roberto; MORAN, Timothy. Unveiling Inequality: A WorldHistorical Perspective. New York: Russell Sage, 2009

LIPSET, Seymour; SCHNEIDER, William. The Confidence Gap. Baltimore: Johns Hopkins University Press, 1983.

MARKOFf, John. Waves of Democracy: Social Movements and Political Change. Thousand Oaks, CA: Pine Forge Press, 1996.

MARKOFF, John. A Moving Target: Democracy. Archives Européennes de Sociologie/European Journal of Sociology, v. 52, n. 2, p. 239-276, 2011.

MIERS, Suzanne. Slavery in the Twentieth Century: The Evolution of a Global Pattern. Walnut Creek, CA: AltaMira Press, 2003.

MILL, John Stuart. On Liberty. New Haven: Yale University Press, 2003.

MORAVCSIK, Andrew. The Origins of Human Rights Regimes: Democratic Delegation in Postwar Europe. International Organization, v. 54, p. 217-252, 2000.

MORRISON, Bruce William; (Ed.) Transnational Democracy in Critical and Comparative Perspective: Democracy's Range Reconsidered. London: Ashgate Publishing, 2004.

NORRIS, Pippa. (Ed.) Critical Citizens: Global Support for Democratic Governance. Oxford University Press, Oxford, 1999.

NORRIS, Pippa. Democratic Deficit: Critical Citizens Revisited. Cambridge: Cambridge University Press, 2011.

NYE JUNIOR, Joseph; ZELIKOW, Philip; KING, David. Why People Don't Trust Government. Cambridge, MA: Harvard University Press, 1997.

OBER, Josiah. What the Ancient Greeks Can Tell Us About Democracy, Annual Review of Political Science, v. 11, p. 67-91, June 2008.

O'DONNELL, Guillermo; CULLELL, Jorge Vargas; IAZZETTA, Osvaldo. (Eds.) The Quality of Democracy: Theory and Practice. Notre Dame, IN: University of Notre Dame Press. 2004.

OSTWALD, Martin. Freedom and the Greeks. In: Davies, Richard. The Origins of Modern Freedom in the West. Stanford: Stanford University Press, 1995. p. 35-63. PALMER, Robert. Notes on the Use of the Word "Democracy" 1789-1799. Political Science Quarterly, v. 68, n. 2, p. 203-226, June 1953. 
PARKER, Harold. The Cult of Antiquity and the French Revolution: A Study in the Development of the Revolutionary Spirit. New York: Octagon Books, 1965.

PATTERSON, Orlando. Freedom in the Making of Western Culture. New York: Basic Books. 1991.

PHARR, Susan; PUTNAM, Robert. (Eds.) Disaffected Democracies: What's Troubling the Trilateral Countries? Princeton: Princeton University Press, 2000.

PRZEWORSKI, Adam. Freedom to choose and democracy. Economics and Philosophy, v. 19, n. 2, p. 265-279, Oct. 2003.

PRZEWORSKI, Adam. Capitalism, Democracy, and Science. In: Munck, Gerardo L.; Snyder, Richard. Passion, Craft, and Method in Comparative Politics. Baltimore: Johns Hopkins University Press, 2007. p. 456-503.

PRZEWORSKI, Adam. Democracy and the Limits of Self-Government. Cambridge: Cambridge University Press, 2010.

PRZEWORSKI, Adam, ALVAREZ, Michael; CHEIBUB, José Antonio; LIMONGI, Fernando. Democracy and Development: Political Institutions and Material Well Being in the World. Cambridge: Cambridge University Press, 2000.

ROSANVALLON, Pierre. Le peuple introuvable: Histoire de la représentation démocratique en France. Paris: Gallimard, 1998.

SCHUMPETER, Joseph. Capitalism, Socialism and Democracy. London: Allen and Unwin, 1943.

SMITH, Dennis; WRIGHT, Sue. (Eds.) Whose Europe? The Turn Towards Democracy. Oxford: Blackwell; Sociological Review, 1999.

SMITH, Jackie. Social Movements for Global Democracy. Baltimore: Johns Hopkins University Press, 2008.

SMITH, Jackie et al. Global Democracy and the World Social Forums. Boulder, CO: Paradigm Publishers, 2008.

SMITH, Jackie; REESE, Ellen; BYRD, Scott ; SMYTHE, Elizabeth. (Eds.) Handbook on World Social Forum Activism. Boulder, CO: Paradigm Publishers, 2011.

TILLY, Charles. Contention and Democracy in Europe, 1650-2000. Cambridge: Cambridge University Press, 2004.

TILLY, Charles. Democracy. Cambridge: Cambridge University Press, 2007.

TOCQUEVILLE, Alexis de. Democracy in America. New York: Knopf. 1994. 2 v.

WALLERSTEIN, Immanuel. World-Systems Analysis: An Introduction. Durham: Duke University Press, 2004.

WRIGHT, Erik Olin. Envisioning Real Utopias. London: Verso, 2010. 